\title{
Decision-making and cash spending patterns of adolescent girls and young women participating in a cash-transfer intervention in Tanzania: Implications for sexual health
}

\author{
Joyce Wamoyi ${ }^{a}$, Peter Balvanz ${ }^{\mathrm{b}}$, Margaret W. Gichane ${ }^{\mathrm{b}}$, Suzanne Maman ${ }^{\mathrm{b}}$, \\ Samuel Mugunga ${ }^{a}$, Esther Majanic and Audrey Pettifor ${ }^{\mathrm{d}, \mathrm{e}}$ \\ ${ }^{a}$ National Institute of Medical Research, Mwanza, Tanzania; ${ }^{b}$ Department of Health Behavior, Gillings School of Global \\ Public Health, University of North Carolina at Chapel Hill, Chapel Hill, NC, USA; 'Sauti Program USAID Grantee, Dar Es \\ Salaam, Tanzania; 'Department of Epidemiology, Gillings School of Global Public Health, University of North Carolina \\ at Chapel Hill, Chapel Hill, NC, USA; ${ }^{\mathrm{e}}$ Carolina Population Center, University of North Carolina at Chapel Hill, Chapel \\ Hill, NC, USA
}

\begin{abstract}
Although cash transfers $(C T)$ have been recommended as a strategy to address structural drivers of HIV, the evidence of the effects of CT on sexual risk and HIV outcomes is mixed. This could partly be due to CT implementation dynamics and beneficiary interpersonal factors. We conducted an assessment of CT component of the DREAMS programme in Tanzania. We explored how AGYW spent their CT over time, to whom they disclosed cash receipt, and where they sought advice on CT use. The study employed qualitative research methods including: 20 longitudinal in-depth interviews (IDIs) and 60 cross-sectional IDIs with AGYW in the CT programme. Data were analysed thematically. AGYW use of CT fell into five categories: business development, survival, self-care, helping family, and savings. The primary uses of CT funds were investment in businesses and livestock for savings. AGYW use of cash changed over instalments. AGYW consulted a variety of sources when deciding on how to use the cash, primarily mothers, programme personnel, and long-term partners/ husbands. CT programmes that give cash directly to AGYW and have a strong entrepreneurial mentorship component could have implications for HIV prevention, $\mathrm{SRH}$, and overall social and economic development.
\end{abstract}

\section{ARTICLE HISTORY}

Received 22 May 2019

Accepted 21 October 2019

\section{KEYWORDS}

Cash transfers; Adolescent girls; Young women; Sexual and Reproductive Health; Tanzania

\section{Introduction}

As adolescent girls and young women (AGYW) in sub-Saharan Africa transition into adulthood, they are faced with a multitude of structural and interpersonal challenges, including poverty and lack of access to economic resources; gender-based violence; and limited access to education and healthcare (UNAIDS \& the African Union, 2015). These challenges increase women's vulnerability to high risk sexual behaviours such as concurrency, age-disparate relationships and transactional sex, which in turn increase risk of HIV infection. Interventions that address these structural determinants are needed.

Cash transfers (CT) are a structural intervention that have been widely used in low- and middleincome countries as a mechanism to alleviate poverty (Cluver, Orkin, Yakubovich, \& Sherr, 2016; Dake et al., 2018; Handa et al., 2015; Palermo et al., 2017). CT have been associated with benefits such as increased school enrolment, reduced unplanned pregnancy and a reduction in early marriage 
(Baird, Garfein, McIntosh, \& Ozler, 2012; Cluver et al., 2013; Dake et al., 2018; Pettifor et al., 2016). One of the key mechanisms through which CT is speculated to reduce HIV risk has been through increasing access to income which in turn reduces need to engage in transactional sex for personal needs. However, evidence on the effects of CT on reducing sexual risk behaviours, and HIV has been mixed. While some studies show a positive effect on outcomes such as reduced HIV incidence and diminished HIV risk behaviours (Baird et al., 2012), others had no influence on HIV incidence or risk behaviour (Pettifor et al., 2016). Evidence on impact of CT on early marriage and pregnancy is also mixed (Baird et al., 2012; Dake et al., 2018; Handa et al., 2015). A possible explanation for the inconsistent results might be differences in context and programme design. These factors may alter whether the young woman has direct access to the cash, amount of cash, and how AGYW use the cash. Despite some evidence from South Africa on the spending of CT money among adolescent girls receiving CT conditioned on school attendance, (MacPhail et al., 2017), little is known about how AGYW out of school, married and unmarried and receiving unconditional CT money, make decisions on spending, and how their spending decisions may change throughout the duration of the CT programme. This dearth of knowledge limits our understanding of the impact of the CTs as a structural intervention to reduce HIV risk among out-of-school AGYW. Understanding how AGYW perceive and use the money received through CT interventions has important implications for their economic empowerment and reduction of risky sexual behaviours.

We present findings from a qualitative study conducted among AGYW who participated in a CT intervention which was implemented as part of the DREAMS (Determined, Resilient, Empowered, AIDS-free, Mentored, and Safe) initiative (PEPFAR et al., 2016), a combination HIV prevention programme targeting AGYW in Tanzania. We explored participants use of cash, changes over time in their spending, and decision making on the use of cash.

\section{Methods}

\section{Sauti programme}

This qualitative study was conducted with participants from Sauti project which was implemented as part of the DREAMS initiative, a USAID funded programme. The programme combines biomedical, behavioural, and structural intervention to address HIV among vulnerable populations, including AGYW. In particular, we focused on participants who had received one of Sauti's structural interventions, a combined CT and economic empowerment programme. The structural intervention aims to provide vulnerable AGYW with cash on a regular basis in order to reduce economic vulnerability thus enabling them to make healthier sexual decisions. Specifically, the programme aims to reduce transactional sex, relationships with older partners, concurrent partnerships, and inconsistent condom use.

Programme participants received CT of TZS 70,000 (\$31) every three months over an 18-month period. Cash was delivered via SIM cards on mobile phones provided by Sauti project. The CT was paired with WORTH+, an economic empowerment intervention which included financial literacy education, individual and group savings and loan, and entrepreneurship skills.

To be eligible for the CT and WORTH+ programme, participants had to be: female; between the ages of 15 and 23; resident of the intervention villages; out of school; completed $10 \mathrm{~h}$ of behaviour change communication (BCC); and, willing and able to give voluntary, informed consent/assent to all study procedures including HIV and HSV-2 testing and receive test result. Participants under age 18 required the consent of a guardian unless they met criteria for emancipated minors.

\section{Data collection}

We recruited participants $(n=60)$ from Sauti sites in the Shinyanga region of Northwest Tanzania, including Bulungwa (rural), Kahama (peri-urban), and Shinyanga municipal (urban). Shinyanga is a 
primarily agricultural area and among the poorest regions of Tanzania. We conducted longitudinal in-depth interviews $(n=20)$, cross sectional in-depth interviews at endline $(n=40)$.

Longitudinal interviews $(n=20)$ were conducted to examine patterns of CT use and their impact over a one-year period. Participants were interviewed in June 2017 just after the first round of CT, then again in June 2018 after participants had received three or four payments. Longitudinal interviews were conducted with participants from Shinyanga municipal since the CT intervention was launched in this region first.

Cross-sectional interviews $(n=40)$ were conducted in June 2018 in all three recruitment areas. Interviews broadly assessed how participants spent their CT, to whom they disclosed cash receipt, how these people reacted to the programme and any advice they provided.

All interviews with AGYW were conducted in Kiswahili by trained female research assistants. Individual interviews were conducted in private locations at the social service organisations implementing Sauti and near the homes of some participants. Participants were compensated TZS 5,000 (\$2) for transportation costs to the interview. We obtained IRB approval from the National Institute for Medical Research in Tanzania and the University of North Carolina. Informed consent was obtained prior to any interview.

\section{Analyses}

All interviews were transcribed verbatim in Kiswahili, and then translated into English. Six researchers coded transcripts using Dedoose, an online qualitative software. We used applied thematic analysis to analyse interviews. For quality control, one transcript from each interview type was coded by all researchers, and then coding consistency was compared across researchers. Upon reaching consensus and modifying code definitions, interviews were coded by multiple researchers. Approximately $20 \%$ of the rest of the transcripts were quality checked for coding. Researchers would take notes on any discrepancies in coding found, and then share with the group in team meetings. After coding was complete, created matrices summarising major topical areas including: participants use of cash, changes over time in their spending, and decision making on the use of cash. We reviewed matrices to identify patterns within and across interviews.

\section{Results}

\section{How AGYW used the cash transfer money}

We noted five primary categories of how participants used the CT money received: survival, self-care, helping family members, business development and savings. Relative amounts of investment by participants varied by a number of different demographic factors, including family support, age, marital status, and residence (urban and rural). Participant's family economic status determined business investment. Families with higher economic status often invested in AGYW's business while in lower income families, AGYW had to provide support instead. In as much as the majority of participants appreciated being in the CT programme, they preferred the amount of cash to be higher than what they were currently receiving. They also expressed a desire for the CT programme to be continuous in order for them to sustain the different investment activities they had started. We present the spending patterns in detail below.

\section{Survival}

Most young women mentioned spending at least some of their money on basic survival items such as food, for themselves and their family. Other survival expenses for self and family included medical expenses and on rare occasions rent. These expenses were not uncommon at each transfer, but 
infrequently were mentioned as the primary use of the cash, especially among the married young women. One participant explained how the money helped with food:

Maybe there is no food. They [family] can ask you for money to buy food. If I have money, I buy, and we eat. [17-year-old girl, single, urban]

Another participant explained how it helped with housing:

I received 70,000 through those phones from Sauti. After I received that money, I thanked God. It helped me ... house rent was due. So, I paid for two months. [19-year-old young woman, married, urban]

\section{Self-care}

Most participants, especially the older unmarried women, mentioned spending portions of the CT on self-care. Self-care involved the purchase of basic personal items as well as taking care of the needs of their children. The bulk of these personal items included soaps, lotions, body oils, and sanitary pads for themselves, and some bought shoes or clothing for themselves or their child.

When I received that money, I bought clothes, sanitary pads, or other important things. [18-year-old girl, single, rural]

\section{Helping family members}

A number of CT recipients mentioned giving some or all of the money received to a family member or husband. The funds AGYW provided were generally intended for food for the family, contributing to a family business or farming expenses, and emergencies. Many AGYW saw it as their duty to help support their family as this was the first time, they had access to money and could contribute financially. One participant explained in regards to food:

After I joined the project, mum sometimes asks for money from me to buy stuff from the market ... .to buy sardines and tomatoes... I even buy meat for them ... I started buying just after I started receiving money, because I thought since had some money, I could help them too ... [16-year-old girl single, rural]

A few supported other family needs such as supporting siblings' education by buying school supplies and paying fees. A participant explained in regards to furthering the education of a sibling.

The first phase I gave the money to my sibling who was going to school ... I gave her/him the entire TZS 70,000.

[24-year-old young woman, single, urban]

\section{Business development}

Almost all young women participating in the CT programme used some of the money for economic development and the most commonly stated primary uses included investment in a personal business and/or purchase of livestock. Common businesses they invested in were: selling powdered soap, clothes, farm produce, cooked food, raising livestock for sale, and tailoring. Those with pre-existing businesses generally added to the capital to expand or diversify their product. Those new to business generally started an enterprise that aligned with Sauti-offered entrepreneurship trainings, invested and participated in a family business, or invested in livestock. A participant new to business explained:

... I used the money to start a business for food vending ... I didn't buy everything ... but started by buying things like tables, those are a must to have.... I started my business with TZS 50,000 (\$24). [23-year-old young woman, single, urban]

Most of the participants who invested in livestock were mainly from the rural setting. Livestock served a dual purpose as entrepreneurial venture to expand and sell animals, and as a form of savings to liquidate later and invest in another venture. 
One participant explained this investment:

"When I received the cash, I withdrew and went to buy three goats ... My plans are that later those goats will grow and reproduce." [21-year-old, young woman, single, urban]

\section{Savings}

Almost all AGYW talked about saving some of the cash from the programme or profits from businesses started with the programme money. Participants mentioned numerous avenues to save money, including mobile money stored on phones (M-pesa and Tigo pesa), livestock (e.g. goats, chickens), a box at home (piggy bank), relatives holding onto their money (especially mothers), and savings groups. The most commonly reported saving mechanism was through saving groups. Saving groups contained 20 or more members and required minimal weekly deposits with optional supplemental deposits. These saving groups provided loans with a small interest rate to enable members expand businesses or cover emergency situations in their lives. One participant commented on planned use of savings:

I have plans with my savings in the group. Once we dissolve the group, I will give the money to mother, so that she can add to it what she has and buy the sewing machine that she wants to buy for me ... in the group I have TZS 50,000 (\$24), but the sewing machine is TZS 200,000 (\$96) [18-year-old girl, single, rural].

Many participants viewed savings groups as secure mechanism through which to build capital and access social support as well as share business ideas. Rather than being tempted to spend or give cash saved at home, money saved in a group was accessible only at certain times and with the knowledge of the group. One participant explained

These groups are okay because you can invest in them and later benefit. If you stay with the money, you can easily use it, but if you save it in the group, it generates interest. [18-year-old girl, single, rural]

Saving groups also served as insurance for emergencies. AGYW mentioned that they borrowed money for emergencies such as sickness and bereavement. A young woman who was encouraged to join a saving group for this reason reported:

Before joining the CT programme, I did not have a group. Then I got to join one where we help each other in times of sickness and during hard times [24-year-old young woman, single, urban]

\section{Changes in how AGYW used cash transfers over time}

The patterns of CT use changed over instalments. Some AGYW mentioned survival and self-care as the primary uses of their first CT; however, in later instalments this number decreased as most focused on economic development.

Honestly, when I received my first cash, that first instalment, I did not invest in business. I bought clothes and food. The second round I used the money to start a business of selling bed sheets. I used the third instalment on farming, but also bought more chickens. I only had two chickens, so when I received, I added more chickens. [16-year-old girl, single, urban]

Everyday demands and challenges interfered with how participants used the CT money. Many talked about being compelled to redirect the money they had invested in business to help with family issues such as illness of family member or their own child. Additionally, events such as the arrival of a child altered the plans girls had for the CT money. One participant explained:

I invested in my clothing business but after having my child I used all that money ... Before I could just spend the money on my clothes, shoes, inner wear but now that I have a child, I have to at least buy him soap [19-yearold young woman, single, urban]

While business expenses and livestock were the two biggest investments at the first instalment, the number of participants listing business as their primary use of cash increased at each instalment. One participant explained her experience with this change over time: 
I used the first and second round of cash with no reasonable target ... but I realized that the way I was using money whenever I got it, I would be broke, ... . I decided to do something profitable ... that will increase my income. [18-year-old girl, single, urban]

\section{Changes in business activities}

Some participants grew a primary business at each transfer by pooling profits from previous CT investments with new CT. In some instances, participants would initially sell from home or rent space and materials necessary to support their business. As their business capital increased these participants would buy needed materials and rent space in a more prominent area. As one participant explained:

I used it to start a business. I opened a restaurant at home for cooking food ... To increase the money, to have my own money. After receiving the second instalment, I left home, I looked for a room for selling my food there". [18-year-old, single girl, urban]

For some participants meeting long term business goals proved challenging. These young women reported not finding a market for their sale items, livestock dying from disease or poisoning, customers buying on credit and not repaying, and consuming produce intended for sale. AGYW were careful not to operate at a loss, and in response to these business difficulties many reported changing businesses. One participant explained in response to inquiry:

... In the shoe and soap business, people delayed paying their debts and sometimes they totally didn't pay. The challenge was big! I saw it was better to pull-up myself from another perspective by deciding to buy chicken, because chicken would not challenge me so much as it was with soap [18-year-old, single girl, urban]

Distribution of cash within personal businesses changed over time as well. Some participants diversified businesses, observed market trends, then focused efforts on the enterprise with the most profit potential at any given time. A young woman talked about how she had moved from one business to another:

At first, I sold the goats I had bought using the second CT. Thereafter, I withdrew [from the phone] cash for the third CT and used the money to buy bags of rice. I have stored the rice ... waiting for the market price to increase so as to sell it. [18-year-old, single girl, rural]

\section{Decision making on the use of cash}

In addition to individual decision making, majority of AGYW also consulted a variety of sources when deciding how to spend money received through the programme. Most AGYW noted numerous individuals that influenced or advised them on how to use the cash. Most notable among these influencers included mothers, longer term or more serious partners/husbands, and Sauti project personnel.

\section{Making financial decisions with parents}

The younger women consulted mothers on financial management and business ideas more than the older ones. Therefore, the businesses they invested in seemed to be heavily determined by their mothers. In addition to helping with decision making on how to use the cash, some mothers also supported the AGYW by adding to the CT money to support business development. A 16-yearold talked about her experience in the following:

My mother is the one who gave me more money because the price for tomatoes had gone up ... She added me TZS 10,000 (\$4). My parents give me ideas. When I share my plan about what I want to do such as to buy livestock ... dad will help me. [16-year-old girl, single, urban] 
Adolescents who were single and did not have prior entrepreneurial skills relied heavily on parental advice regarding how to spend the money. Many unmarried AGYW preferred to disclose their involvement in the CT programme to family members rather than sexual partners. They talked about trusting and confiding in their mothers most for almost all matters in their lives including their participation in the CT programme.

My mother is the most important person to me because she means everything to me ... I cannot do anything without involving my mother, even when I wanted to join the CT project, I went and told her first and she advised me to join. [17-year-old girl, single, urban]

Most AGYW reflected on the usefulness of the advice they received from their mothers and said that without consulting them, they would have misused the money by spending it on non-income earning items such as clothing:

I feel that had it not been for my mum's advice, I think I would have misused the money .... I would have bought clothes and the money would have gone to waste. It is good that I involved mother. [18-year-old girl, single, rural]

\section{Making financial decisions with partners}

The majority of the married AGYW disclosed their involvement in the CT programme to their spouses who sometimes helped them make decisions on how the cash should be used. Husband's advice was mainly in favour of the cash being used for the general development of the family. A married woman described how her partner had been supportive but also controlling in the following:

He [husband] would help me weigh my priorities and advise me on what I should give more priority to, if I have money, he would top it up and advise me on what to do with it" ... "but he is also very strict. Once I receive the money, he starts making plans for me, he asks what I am going to do with the money, and I tell him what I want to get with the money," [22-year-old young woman, married, urban].

On the contrary, unmarried AGYW seldom disclosed receipt of CT to casual and non-serious partners. These participants thought their partners would take money from them, control their money, and stop giving them money often through transactional sex. One participant explained:

As for me, I felt that if I told him that I am in CT project, he would not have helped me when I had a problem and asked him for money. I felt that he wouldn't really listen to my problem if he knew I was receiving the cash.

[18-year-old girl, Single, urban]

\section{The influence of the programme on the use of CT}

Sauti project personnel had a large influence on young women's use of cash. Through regular entrepreneurial and financial training sessions, the intervention messaging on how to spend CT money and the need to save through savings groups enhanced AGYW's decision-making ability and cash management skills. AGYW recounted advice from the programme trainers on investing their money in something that could generate profits rather than consumables. A 17-year-old girl reported:

They advised us that we should do business so that we can be getting profit ... It is good that they advised us to do business ... We are now doing well ... Our lives have become better. [17-year-old girl, single, urban]

Another participant reflected on a message recalled from the training sessions on the use of cash for investment in business.

When we went to the session the teacher gave us constructive ideas, that "you need to make progress because this money is meant to facilitate your development, it's not intended to be spent on your clothes or shoes, because it will be useless". [22-year-old young woman, married, urban] 


\section{Discussion}

This study provides insights into spending patterns and decision making on spending by AGYW enrolled in a CT intervention. AGYW demonstrated interest in improving their economic situation by investing in income-generating businesses with CT funds. The use of the CT was influenced by AGYW's family context and baseline levels of poverty, prior business experience and CT programme messaging. AGYW's decision on how to use the cash for business development were sometimes determined by factors such as: previous experience doing business, parental advice, husband support, immediate family economic need and the occurrence of life events such as sudden illness. While many of the younger women struggled to decide what business activity to invest their CT money, this was not entirely the case for the older participants with prior entrepreneurial skills.

AGYW's consultation of parents, other family members and CT programme implementers for decision making on how to use the cash, suggests that they could benefit from formal mentorship. Despite concerns that parents would take and spend the money in ways that might not benefit AGYW, there are calls for mentorship to accompany financial interventions with young populations in Tanzania (Balvanz et al., 2018). Mentorship can help direct AGYW on how to save or invest the money in an informed manner, including saving to promote resiliency in the face of adversities such as fluctuations in market prices, failed farm produce and customers who default on repayments of items taken on credit.

It is apparent from our findings that AGYW need to spend some money on basic-personal needs but over time they can develop business to generate income for these needs and more. We observed that the structure and amount of transfers impacted development over time with many showing improved business management skills through subsequent rounds of CTs. The variations in AGYW's use of cash by instalments could point to their flexibility and sensitivity to market situations and fluctuations. The changes in use of cash from survival and self-care in their first cash instalments to more income generation activities in later instalments is a sign that once AGYW are helped to cater for their immediate basic needs, they are willing to invest in a system that ensures them regular income.

Cash enhanced AGYW financial stability enabling AGYW to participate in social and economic savings groups. The discussions in the savings groups permitted for the exchange of ideas and allowed for interpersonal support especially on how to use the cash. Saving groups also offered a safety net in emergencies such as sudden illness, or death of a close family member therefore reducing AGYW's experience of stress. Saving groups could have implications for the success of CT programmes that directly give the cash to AGYW. There is need for CT programmes to encourage recipients to form social support groups that could act as insurance in times of need.

This CT programme studied here differs from others in that the lump-sum amount of cash was directly given to AGYW at an interval of three months, and AGYW were mentored on wise spending and left to make their own decisions on how to spend. This strategy allowed AGYW access large sums of their own cash. Other CT programmes in Tanzania such as the government's productive Safety Social Net and elsewhere have mainly given cash to caregivers for vulnerable households and expected them to spend the cash in a manner that would benefit all in the household including AGYW(Handa et al., 2017; Pettifor et al., 2013). Although studies have shown that CT given to caregivers (especially female caregivers) improved child outcomes(Cluver et al., 2013), the effects could be even greater when the cash is given to both the adolescents and caregivers(Baird et al., 2012). Our results point to many benefits to AGYW if they are given CT money directly. Evidence shows that the needs and wants of AGYW might differ from what parents/caregivers might consider important and be willing to provide for them, thus leading AGYW to engage in risky sexual behaviour such as transactional sex, multiple partners to able to meet their needs(Babalola, Tambashe, \& Vondrasek, 2005; Baird et al., 2012; Bhana \& Pattman, 2011; Cluver, Orkin, Boyes, Gardner, \& Meinck, 2011; Leclerc-Madlala, 2003; Wamoyi, Wight, Plummer, Mshana, \& Ross, 2010; Zembe, Townsend, Thorson, \& Ekstrom, 2013). We recommend further research to understand the variations in effect if cash 
is given to both AGYW versus just parents or AGYW in the same setting. There is also need to explore the sustainability of the benefits reported by AGYW after the conclusion of the CT programme.

The everyday challenges in AGYW's lives interfered with some investment plans which limited achievement of business goals and overall benefits from the CT. Challenges such as livestock dying and businesses not doing well could indicate that the programme was positive but not sufficient, and additional linkages/services are needed, such as linkages to agricultural extension workers who can teach people buying livestock about caring for them as well as proper entrepreneurial mentorship.

While on one hand we had participants who needed to help their families with basic needs, on the contrary, there were those who received additional cash from parents for their business. As many encountered emergencies such as illness and siblings school fees, they were forced to redirect their resources, leading to deterioration of business and less financial returns (Dunbar et al., 2010). We speculate that the lack of effects on some health outcomes in previous CT programmes could be explained by how the money was spent by the beneficiaries (Baird et al., 2012; Cluver et al., 2011; Handa et al., 2015). CT programmes should encourage AGYW to have a backup plan to fall back to during emergencies. Failure to do this could mean that the full benefits of CT given to AGYW directly may not have the desired impact.

Similar to findings from other CT interventions in Tanzania (Palermo et al., 2017), this programme seemed to have reduced poverty experienced by AGYW as indicated in their mention that they could now afford things that that they could not previously buy without the CT intervention. Similar to what was observed in other CT studies, (Baird et al., 2012; Handa et al., 2015), our findings show that the CT helped address the economic drivers of risk as AGYW talked about CT funds and savings for survival needs and emergencies. In many low-income household families, AGYW have been expected to contribute to household needs as it is not always feasible for parents to provide for all basic needs. Previous work points to adolescent supporting such families through money earned as a result of engaging in transactional sex (Wamoyi et al., 2010; Wight et al., 2006). As indicated in our findings, AGYW are still supporting their families' economic needs, but mainly through CT programme money and less from their engagement in transactional sex. AGYW's concern with domestic affairs and support of other household members using their CT has also been noted in another study in South Africa (Khoza et al., 2018). AGYW access to their own cash could have implications for their sexual and reproductive health (SRH). As noted in other studies from Tanzania AGYW were motivated to engage in premarital sex to afford survival items (Maganja, Maman, Groves, \& Mbwambo, 2007; Wamoyi et al., 2010). In another paper from this study (Pettifor, Wamoyi, Balvanz, Gichane, \& M, 2019), we observed that AGYW reported reduced risky sexual behaviour such as transactional sex and number of partners as a result of their engagement in the CT programme. Transactional sex is associated with increased risk of HIV among women (Kilburn et al., 2018; Wamoyi, Stobeanau, Bobrova, Abramsky, \& Watts, 2016) and therefore, CT interventions that address the economic vulnerability of AGYW are likely to reduce their engagement in transactional sex and ultimately reduce their risk for HIV infection.

Similar to any research, this study had limitations. This was a qualitative study with limited generalisability. Participants provided self-reports on how the CT was used, thus there is potential desirability bias in their reports of spending patterns. Participants were recruited from an ongoing intervention, the Sauti programme that had a strong financial management component and emphasised the need for AGYW to spend the CT on business and development goals. The other limitation in terms of sample is that these interviews were conducted among the women who stayed in the CT programme - these may have been more successful in their business ventures compared to those who dropped out.

\section{Conclusion}

The CT programme giving cash directly to AGYW as opposed to through parents/caregiver could be a better strategy as it gives them access to their own cash and income allowing them to spend on 
personal-basic needs as well as investment in business activities. AGYW's decision on how to spend the cash was very much influenced by parents and messaging from the CT programme. Further research should explore the progress and sustainability of the business investments by the AGYW post the CT programme. AGYW's CT programmes that have a strong entrepreneurial mentorship component could have implications for HIV prevention as well as other SRH benefits and overall social and economic development.

\section{Acknowledgement}

We are grateful to all the young women who participated in this study. We benefited enormously from the support of staff from Sauti project, HUHESO and RAFIKI civil society organisations who helped with recruitment of study participants and acknowledge their contribution.

\section{Disclosure statement}

No potential conflict of interest was reported by the authors.

\section{Funding}

This study was funded by [grant number OPP1158402] of the Bill and Melinda Gates Foundation.

\section{References}

Babalola, S., Tambashe, B. O., \& Vondrasek, C. (2005). Parental factors and sexual risk-taking among young people in Cote d'Ivoire. African Journal of Reproductive Health, 9(1), 49-65.

Baird, S. J., Garfein, R. S., McIntosh, C. T., \& Ozler, B. (2012). Effect of a cash transfer programme for schooling on prevalence of HIV and herpes simplex type 2 in Malawi: A cluster randomised trial. Lancet, 379(9823), $1320-1329$. doi:S0140-6736(11)61709-1

Balvanz, P., Yamanis, T. J., Mulawa, M. I., Mwikoko, G., Kajuna, D., Kilonzo, M. N., ... Maman, S. (2018). Microfinance and health interventions: Factors influencing loan repayment success with young men in Dar es Salaam, Tanzania. Global Public Health, 1-17. doi:10.1080/17441692.2018.1501079

Bhana, D., \& Pattman, R. (2011). Girls want money, boys want virgins: The materiality of love amongst South African township youth in the context of HIV and AIDS. Culture, Health \& Sexuality, 13(8), 961-972. doi:938424428 [pii] 10.1080/13691058.2011.576770

Cluver, L., Boyes, M., Orkin, M., Pantelic, M., Molwena, T., \& Sherr, L. (2013). Child-focused state cash transfers and adolescent risk of HIV infection in South Africa: A propensity-score-matched case-control study. Lancet Global Health, 1(6), e362-e370. doi:10.1016/S2214-109X(13)70115-3

Cluver, L., Orkin, M., Boyes, M., Gardner, F., \& Meinck, F. (2011). Transactional sex amongst AIDS-orphaned and AIDS-affected adolescents predicted by abuse and extreme poverty. Journal of Acquired Immune Deficiency Syndrome, 58(3), 336-343. doi:10.1097/QAI.0b013e31822f0d82

Cluver, L., Orkin, F., Yakubovich, A., \& Sherr, L. (2016). Combination social protection for reducing HIV-risk behavior among adolescents in South Africa. Journal of Acquired Immune Deficiency Syndrome, 72(1), 96-104. doi:10. 1097/QAI.0000000000000938

Dake, F., Natali, L., Angeles, G., de Hoop, J., Handa, S., Peterman, A., ... the Zambia Cash Transfer Evaluation, T. (2018). Cash transfers, early marriage, and Fertility in Malawi and Zambia. Studies in Family Planning, 49(4), 295-317. doi:10.1111/sifp.12073

Dunbar, M. S., Maternowska, M. C., Kang, M. S., Laver, S. M., Mudekunye-Mahaka, I., \& Padian, N. S. (2010). Findings from SHAZ!: A feasibility study of a microcredit and life-skills HIV prevention intervention to reduce risk among adolescent female orphans in Zimbabwe. Jorunal of Prevention \& Intervention in the Community, 38(2), 147-161. doi:921002122 [pii]10.1080/10852351003640849

Handa, S., Palermo, T., Rosenberg, M., Pettifor, A., Halpern, C. T., \& Thirumurthy, H. (2017). How does a national poverty programme influence sexual debut among Kenyan adolescents? Global Public Health, 12(5), 617-638. doi:10.1080/17441692.2015.1134617

Handa, S., Peterman, A., Huang, C., Halpern, C., Pettifor, A., \& Thirumurthy, H. (2015). Impact of the Kenya cash transfer for orphans and vulnerable children on early pregnancy and marriage of adolescent girls. Social Science Medicine, 141, 36-45. doi:10.1016/j.socscimed.2015.07.024 
Khoza, N., Stadler, J., MacPhail, C., Chikandiwa, A., Brahmbhatt, H., \& Delany-Moretlwe, S. (2018). Cash transfer interventions for sexual health: Meanings and experiences of adolescent males and females in inner-city Johannesburg. BMC Public Health, 18(1), 120. doi:10.1186/s12889-018-5027-3

Kilburn, K., Ranganathan, M., Stoner, M. C. D., Hughes, J. P., Macphail, C., Agyei, Y., ... Pettifor, A. (2018). Transactional sex and incident HIV infection in a cohort of young women from rural South Africa enrolled in HPTN 068. Aids (london, England), doi:10.1097/QAD.0000000000001866

Leclerc-Madlala, S. (2003). Transactional sex and the pursuit of modernity. Social Dynamics, 29(2), 213-233. doi:10. $1080 / 02533950308628681$

MacPhail, C., Khoza, N., Selin, A., Julien, A., Twine, R., Wagner, R. G., ... Pettifor, A. (2017). Cash transfers for HIV prevention: What do young women spend it on? Mixed methods findings from HPTN 068. BMC Public Health, 18 (1), 10. doi:10.1186/s12889-017-4513-3

Maganja, R. K., Maman, S., Groves, A., \& Mbwambo, J. K. (2007). Skinning the goat and pulling the load: Transactional sex among youth in Dar es Salaam, Tanzania. AIDS Care, 19(8), 974-981.

Palermo, T., Kilama, B., Prencipe, L., de Hoop, J., Groppo, V., \& P, A. (2017). Tanzania youth study: Productive Social Safety Net (PSSN) Impact evaluation: Endline report. UNICEF Office of Research and REPOA (Publication no. Retrieved from https://reliefweb.int/sites/reliefweb.int/files/resources/BASELINE20REPORT20FOR\%20WEB. pdf). from UNICEF Office of Research - Innocenti. Florence.

PEPFAR, BMGF, GirlEffect, Johnson\&Johnson, ViiV Healthcrae, \& Gilead. (2016). DREAMS core package of interventions summary (Publication no. Retrieved from https://www.pepfar.gov/documents/organization/269309.pdf).

Pettifor, A., Bekker, L. G., Hosek, S., DiClemente, R., Rosenberg, M., Bull, S. S., ... Committee, H. I. V. P. T. N. A. S. (2013). Preventing HIV among young people: Research priorities for the future. Journal of Acquired Immune Deficiency Syndrome, 63(Suppl 2), S155-S160. doi:10.1097/QAI.0b013e31829871fb

Pettifor, A., MacPhail, C., Hughes, J. P., Selin, A., Wang, J., Gomez-Olive, F. X., ... Kahn, K. (2016). The effect of a conditional cash transfer on HIV incidence in young women in rural South Africa (HPTN 068): A phase 3, randomised controlled trial. Lancet Global Health, 4(12), e978-e988. doi:10.1016/S2214-109X(16)30253-4

Pettifor, A., Wamoyi, J., Balvanz, P., Gichane, W., \& M, S. (2019). Cash plus: Exploring the mechanisms through which a cash transfer plus financial education programme in Tanzania reduced HIV risk for adolescent girls and young women. Journal of the International AIDS Society, 22(S4), e25316. doi:10.1002/jia2.25316

UNAIDS \& the African Union. (2015). Empower young women and adolescent girls (Publication no. Retrieved from http://www.unaids.org/sites/default/files/media_asset/JC2746_en.pdf). from UNAIDS.

Wamoyi, J., Stobeanau, K., Bobrova, N., Abramsky, T., \& Watts, C. (2016). Transactional sex and risk for HIV infection in sub-Saharan Africa: A systematic review and meta-analysis. Journal of Internation AIDS Society, 19(1), 20992. doi:10.7448/IAS.19.1.20992

Wamoyi, J., Wight, D., Plummer, M., Mshana, G. H., \& Ross, D. (2010). Transactional sex amongst young people in rural northern Tanzania: An ethnography of young women's motivations and negotiation. Reproductive Health, 7 (1), 2.

Wight, D., Plummer, M. L., Mshana, G., Wamoyi, J., Shigongo, Z. S., \& Ross, D. A. (2006). Contradictory sexual norms and expectations for young people in rural Northern Tanzania. Social Science and Medicine, 62(4), 987-997.

Zembe, Y. Z., Townsend, L., Thorson, A., \& Ekstrom, A. M. (2013). "Money talks, bullshit walks" interrogating notions of consumption and survival sex among young women engaging in transactional sex in post-apartheid South Africa: A qualitative enquiry. Globalization and Health, 9, 28. doi:10.1186/1744-8603-9-28 